\title{
The sagittal abdominal diameter : Role in predicting severe liver disease in the general population
}

\section{Åberg, Fredrik}

2018

Åberg , F \& Jula , A 2018 , ' The sagittal abdominal diameter : Role in predicting severe liver disease in the general population ' , Obesity Research \& Clinical Practice, vol. 12 , no. 4 , pp. 394-396 . https://doi.org/10.1016/j.orcp.2018.06.007

http://hdl.handle.net/10138/304173

https://doi.org/10.1016/j.orcp.2018.06.007

publishedVersion

Downloaded from Helda, University of Helsinki institutional repository.

This is an electronic reprint of the original article.

This reprint may differ from the original in pagination and typographic detail.

Please cite the original version. 


\title{
The sagittal abdominal diameter: Role in predicting severe liver disease in the general population
}

\author{
Fredrik Åberg ${ }^{a, *}$, Antti Jula ${ }^{b}$ \\ a Transplantation and Liver Surgery Clinic, Helsinki University Hospital, Helsinki University, Helsinki, Finland \\ ${ }^{\mathrm{b}}$ Department of Health, National Institute for Health and Welfare, Turku, Finland
}

\section{A R T I C L E I N F O}

\section{Article history:}

Received 28 February 2018

Received in revised form 24 May 2018

Accepted 18 June 2018

\section{Keywords:}

Obesity

Liver cirrhosis

SAD

BMI

Waist-hip ratio

\begin{abstract}
A B S T R A C T
The role of the sagittal abdominal diameter (SAD) as a predictor of incident liver disease is unknown. 6626 individuals from the Finnish population-based Health 2000 Study were linked with national registers for liver-related admissions, mortality and cancer. SAD predicted incident liver disease (HR $1.32,95 \% \mathrm{CI}$ 1.06-1.65) when adjusted for age and sex, but the association was weaker than for waist-hip ratio (HR $1.86,95 \%$ CI 1.35-2.55), waist circumference (HR 1.42, 95\% CI 1.12-1.81), and waist-height ratio (HR 1.44, $95 \%$ CI 1.12-1.87); BMI was non-significant. In conclusion, SAD provided no additional benefit to other obesity measures in predicting incident severe liver disease.
\end{abstract}

(C) 2018 Asia Oceania Association for the Study of Obesity. Published by Elsevier Ltd. All rights reserved.

\section{Introduction}

Obesity is associated with increased risk of liver disease [1]. Beyond absolute fat mass, the distribution of adipose tissue affects the metabolic consequences. Body-mass index (BMI) does not differentiate lean mass from adipose tissue, or central obesity from preferential peripheral fat distribution. Waist circumference (WC) is limited by its inability to differentiate between subcutaneous fat and visceral fat. Recently, the waist/hip ratio (WHR) was suggested as the obesity measure with the strongest association to non-alcoholic fatty liver disease (NAFLD) [2] and incident severe liver disease [3].

The sagittal abdominal diameter (SAD), the height of the abdomen when lying supine, correlates strongly with visceral adiposity and may be a better predictor than other obesity measures of cardiometabolic risk [4,5]. SAD differentiates between subcutaneous fat and visceral fat, because in the supine position, loose subcutaneous fat falls towards the sides due to gravity, whereas harder visceral fat is left to contribute to the SAD measurement.

We analysed the value of SAD in predicting incident severe liver disease in the general population and compared SAD to other anthropometric measures.

\section{Subjects and methods}

Data were from the Finnish population-based Health 2000 Study (2000-2001), a multidisciplinary epidemiologic survey of a nationally representative cohort. Data were collected at baseline through questionnaires, interviews, physical examinations and blood tests. The Health-2000 study is described in detail elsewhere [6,7]. The Epidemiology Ethics Committee of the Helsinki and Uusimaa Hospital Region approved the Health 2000 Study protocol, and all participants provided signed informed consent. Follow-up data until 2014 for liver-related admissions, mortality, and liver cancer (ICD10 codes K70.1-K70.9, K72, K74.0-K74.2, K74.6, C22.0) came from the National Hospital Discharge Register, Statistics Finland, and the Finnish Cancer Registry, respectively. We excluded subjects with baseline liver disease (ICD10 codes K70-K77) $(n=54)$ and those with chronic viral hepatitis at baseline or during follow-up $(\mathrm{n}=17)$.

Baseline SAD, BMI, WC, WHR, and waist/height ratio (WHtR) were entered into Cox regression analyses with various level of adjustment. The covariates were standardised and centred to allow direct comparisons of hazard ratios. The performance of each anthropometric measure was also tested using area-under-thecurve (AUC) by c-statistics.

\section{Results}

The final study cohort comprised 6626 individuals: mean age 54 years (SD 15), 45\% men, mean alcohol consumption $74 \mathrm{~g} /$ week

\footnotetext{
* Corresponding author at: HUCH Meilahti Hospital, PB 372, 00029 HUS, Finland.

E-mail address: Fredrik.Aberg@helsinki.fi (F. Åberg).
} 
Table 1

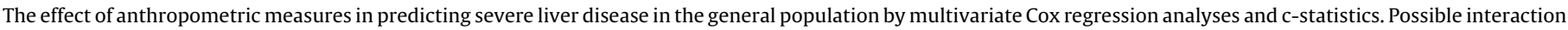
between the SAD and other measures were also tested.

\begin{tabular}{|c|c|c|c|c|c|}
\hline & $\begin{array}{l}\text { Events/at risk } \\
\mathrm{n} / \mathrm{N}\end{array}$ & $\begin{array}{l}\text { Model } 1 \\
\text { HR (95\% CI) }\end{array}$ & $\begin{array}{l}\text { Model } 2 \\
\text { HR (95\% CI) }\end{array}$ & $\begin{array}{l}\text { Model } 3 \\
\text { HR (95\% CI) }\end{array}$ & AUC (95\% CI) \\
\hline $\mathrm{SAD}(\mathrm{cm})$ & & & & & $0.63(0.56-0.70)$ \\
\hline Continuous & & $1.32(1.06-1.65)$ & $1.35(1.08-1.70)$ & $1.32(1.03-1.70)$ & \\
\hline \multicolumn{6}{|l|}{ Quartiles } \\
\hline$<19.5$ & $8 / 1433$ & 1 & 1 & 1 & \\
\hline $19.5-21.5$ & $14 / 1603$ & $1.16(0.48-2.04)$ & $1.41(0.53-3.73)$ & $1.48(0.55-3.95)$ & \\
\hline $21.6-23.5$ & $18 / 1553$ & $1.40(0.60-3.28)$ & $1.80(0.70-4.64)$ & $1.88(0.71-4.98)$ & \\
\hline$>23.5$ & $26 / 1510$ & $2.05(0.90-4.66)$ & $2.44(0.97-6.14)$ & $2.43(0.91-6.48)$ & \\
\hline BMI $\left(\mathrm{kg} / \mathrm{m}^{2}\right)$ & & & & & $0.56(0.49-0.64)$ \\
\hline Continuous & & $1.12(0.88-1.43)$ & $1.16(0.90-1.48)$ & $1.12(0.85-1.46)$ & \\
\hline \multicolumn{6}{|l|}{ Quartiles } \\
\hline$<23.6$ & $14 / 1647$ & 1 & 1 & 1 & \\
\hline $23.6-26.3$ & $15 / 1643$ & $0.78(0.37-1.62)$ & $0.96(0.45-2.08)$ & $1.07(0.49-2.34)$ & \\
\hline $26.4-29.5$ & $20 / 1630$ & $0.98(0.49-1.95)$ & $1.12(0.54-2.31)$ & $1.12(0.52-2.43)$ & \\
\hline$>29.5$ & $23 / 1655$ & $1.21(0.62-2.37)$ & $1.35(0.66-2.78)$ & $1.27(0.58-2.81)$ & \\
\hline $\mathrm{WC}(\mathrm{cm})$ & & & & & $0.67(0.61-0.74)$ \\
\hline Continuous & & $1.42(1.12-1.81)$ & $1.46(1.13-1.88)$ & $1.44(1.09-1.90)$ & \\
\hline \multicolumn{6}{|l|}{ Quartiles } \\
\hline$<83$ & $7 / 1668$ & 1 & 1 & 1 & \\
\hline $83-92.5$ & $13 / 1633$ & $1.26(0.49-3.22)$ & $1.70(0.59-4.89)$ & $1.95(0.67-5.70)$ & \\
\hline $92.6-101.5$ & $18 / 1612$ & $1.43(0.57-3.58)$ & $1.91(0.67-5.44)$ & $2.11(0.72-6.17)$ & \\
\hline$>101.5$ & $34 / 1594$ & $2.61(1.09-6.25)$ & $3.29(1.20-9.00)$ & $3.59(1.23-10.5)$ & \\
\hline WHR & & & & & $0.73(0.66-0.79)$ \\
\hline Continuous & & $1.86(1.35-2.55)$ & $1.81(1.28-2.55)$ & $1.74(1.21-2.50)$ & \\
\hline \multicolumn{6}{|l|}{ Quartiles } \\
\hline$<0.847$ & $4 / 1631$ & 1 & 1 & 1 & \\
\hline $0.847-0.911$ & $8 / 1621$ & $1.76(0.52-5.94)$ & $3.42(0.72-16.3)$ & $3.49(0.73-16.8)$ & \\
\hline $0.912-0.975$ & $21 / 1626$ & $3.77(1.17-12.2)$ & $7.50(1.62-34.8)$ & $8.27(1.75-39.0)$ & \\
\hline$>0.975$ & $39 / 1627$ & $6.28(1.88-21.0)$ & $10.6(2.18-51.2)$ & $10.9(2.16-54.6)$ & \\
\hline WHtR & & & & & $0.63(0.57-0.70)$ \\
\hline Continuous & & $1.44(1.12-1.87)$ & $1.53(1.17-1.99)$ & $1.53(1.15-2.05)$ & \\
\hline \multicolumn{6}{|l|}{ Quartiles } \\
\hline$<49.4$ & $6 / 1492$ & 1 & 1 & 1 & \\
\hline $49.4-54.4$ & $17 / 1566$ & $1.87(0.73-4.81)$ & $2.91(0.97-8.74)$ & $3.24(1.06-9.96)$ & \\
\hline $54.5-60.1$ & $19 / 1505$ & $2.03(0.79-5.23)$ & $2.89(0.96-8.70)$ & $3.15(1.00-9.95)$ & \\
\hline$>60.1$ & $24 / 1521$ & $2.86(1.12-7.30)$ & $4.39(1.46-13.2)$ & $4.78(1.48-15.5)$ & \\
\hline \multicolumn{6}{|c|}{ Interaction terms } \\
\hline $\mathrm{SAD} * \mathrm{BMI}$ & & $1.04(0.90-1.20)$ & $1.02(0.88-1.19)$ & $1.01(0.86-1.20)$ & \\
\hline $\mathrm{SAD} * \mathrm{WC}$ & & $1.01(0.87-1.17)$ & $0.98(0.83-1.16)$ & $0.97(0.81-1.16)$ & \\
\hline SAD * WHR & & $1.13(0.52-2.48)$ & $0.78(0.32-1.90)$ & $1.06(0.78-1.45)$ & \\
\hline SAD * WHtR & & $0.99(0.83-1.17)$ & $0.96(0.79-1.16)$ & $0.95(0.77-1.16)$ & \\
\hline
\end{tabular}

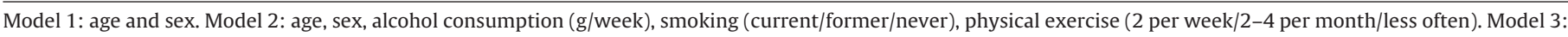
Model 2 + triglycerides, HDL-cholesterol, glucose.

Continuous variables are standardised and centred; thus, HRs reflect changes per standard deviation.

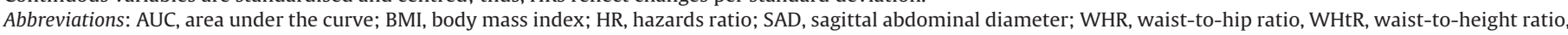
WC, waist circumference.

(SD 145), current smokers $26 \%$, former smokers $22 \%$, diabetes $10 \%$, metabolic syndrome $46 \%$. SAD correlated with BMI $(r=0.85$, $\mathrm{P}<0.001)$, WC $(\mathrm{r}=0.87, \mathrm{P}<0.001)$, WHR $(\mathrm{r}=0.57, \mathrm{P}<0.001)$ and WHtR $(r=0.84, P<0.001)$ when adjusting for age, gender, and alcohol consumption. Correlation between alcohol consumption (g/week) and obesity measures was weak $(r<0.12$ for each obesity measure, adjusted for age and gender).

There were 72 liver events during follow-up. SAD exhibited a significant association with liver disease risk, but the association was weaker than for WHR, WC, and WHtR (Table 1). BMI showed no significant association with incident liver disease (Table 1). WHR exhibited the strongest risk effect for liver disease (Table 1); individuals in the highest quartile by WHR had 6.3-10.6-fold risk for liver disease compared to those in the lowest quartile. WHR exhibited the highest AUC for incident liver disease (Table 1).

There was no interaction effect between SAD and other anthropometric measures (Table 1). SAD remained significant after adjusting for BMI (HR 1.57-1.67, $\mathrm{P}=0.002-0.02$ in models $1-3$ ), but lost significance when adjusting for WC, WHR, or WHtR. SAD was non-significant in each BMI-, WC-, WHR-, or WHtR quartile.
WHR exhibited higher hazard ratios than SAD and other measures also in non-heavy alcohol users (average consumption $<210 \mathrm{~g} /$ week for men and $<140 \mathrm{~g} /$ week for women), absent diabetes, women, men, and individuals aged $<50$ years or $>50$, but WHtR was superior among those with BMI $<25 \mathrm{~kg} / \mathrm{m}^{2}$ (data not shown). SAD was non-significant among non-diabetics. All anthropometric measures were non-significant in subjects with diabetes or heavy alcohol use.

\section{Discussion}

To our knowledge, this is the first longitudinal study comparing SAD to other anthropometric measures in predicting incident severe liver disease in the general population. WHR proved superior to other measures, both with regards to magnitude of risk effect and discriminatory ability. SAD provided no additional benefit. BMI was the poorest predictor. Our results parallel recent findings indicating superiority of WHR compared to BMI and WC in predicting liver disease risk $[2,3,8]$.

Inclusion of the hip circumference in the WHR may, better than the other measures, account for subcutaneous fat in the glute- 
ofemoral region, the so called pear-type obesity, which is common in Caucasians and uncommon in Asians. Low femoral subcutaneous fat was inversely associated with NAFLD in a cross-sectional SouthKorean study [9].

Although SAD predicted incident liver disease, the other anthropometric measures performed better. Further study on the influence of obesity on liver disease should therefore likely focus on the WHR instead of BMI, WC, WHtR or SAD. WHR may be the preferable obesity metric in liver-disease risk assessment and screening, and when assessing response to health interventions targeted at reducing this risk.

\section{Acknowledgements}

We would like to thank all participants of, and persons involved in the conduct of the Health 2000 study.

\section{Ethical statement}

None.

FÅ received research grants from Mary and Georg Ehrnrooth Foundation, Liv och Hälsa, and Finska Läkaresällskapet.

I have read and have abided by the statement of ethical standards for manuscripts submitted to the Obesity Research \& Clinical Practice.

\section{References}

[1] Hagström H, Tynelius P, Rasmussen F. High BMI in late adolescence predicts future severe liver disease and hepatocellular carcinoma: a national, population-based cohort study in 1.2 million men. Gut 2017;(March), http://dx.doi.org/10.1136/gutjnl-2016-313622 [Epub ahead of print].

[2] Zheng RD, Chen ZR, Chen JN, Lu YH, Chen J. Role of body mass index, waist-toheight and waist-to-hip ratio in prediction of nonalcoholic fatty liver disease. Gastroenterol Res Pract 2012;2012:362147.

[3] Andreasson A, Carlsson AC, Önnerhag K, Hagström H. Waist/hip ratio better predicts development of severe liver disease within 20 years than body mass index: a population-based cohort study. Clin Gastroenterol Hepatol 2017;15(8):1294-301.

[4] Öhrvall M, Berglund L, Vessby B. Sagittal abdominal diameter compared with other anthropometric measurements in relation to cardiovascular risk. Int J Obes Relat Metab Disord 2000;24(4):497-501.

[5] Pajunen P, Rissanen H, Laaksonen MA, Heliövaara M, Reunanen A, Knekt P. Sagittal abdominal diameter as a new predictor for incident diabetes. Diabetes Care 2013;36(2):283-8.

[6] Aromaa A, Koskinen S. Health and functional capacity in Finland. Baseline results of the Health 2000 health examination survey. Helsinki, Finland: Publications of National Public Health Institute, Series B 12/2004; 2004, 2016, p. 171.

[7] Åberg F, Helenius-Hietala J, Puukka P, Färkkilä M, Jula A. Interaction between alcohol consumption and metabolic syndrome in predicting severe liver disease in the general population. Hepatology 2018;67(6):2141-9 http://dx.doi.org/10.1002/hep.29631.

[8] Schult A, Mehlig K, Björkelund C, Wallerstedt S, Kaczynski J. Waist-to-hip ratio but not body mass index predicts liver cirrhosis in women. Scand J Gastroentero 2018;53(February (2)):212-7.

[9] Jun DW, Han JH, Kim SH, Jang EC, Kim NI, Lee JS, et al. Association between low thigh fat and non-alcoholic fatty liver disease. J Gastroenterol Hepatol 2008;23(6):888-93. 